\title{
Süt Sığırcılığı İşletmelerinde Irk Tercihi ve Etkileyen Faktörler: Siirt İli Örneği
}

\section{Galip BAKIR ${ }^{1}$, Mehmet Yaşar ÖREN2}

${ }^{1}$ Kahramanmaraş Sütçüimam Üniversitesi, Ziraat Fakültesi Zootekni Bölümü, Kahramanmaraş, ${ }^{2}$ Tarım ve Orman İl Müdürlüğü, Hayvan Sağlığı Şubesi, Siirt, Türkiye

${ }^{1}$ https://orcid.org/0000-0002-0816-227X, ${ }^{2}$ https://orcid.org/0000-0002-1476-8569

凹: galipbakir@hotmail.com

\section{ÖZET}

$\mathrm{Bu}$ araştırma, süt sı̆̆ırcılı̆̆ işletmelerinde ırk tercihi ve etkileyen faktörlerin belirlenmesi amacıyla yapılmıştır. Bu amaçla Siirt ilinde 250 işletmede anket yapılmış ve veriler SPSS 21.0 paket programı ile analiz edilerek çapraz tablolar oluşturulmuştur. İşletmelerde mevcut sığırların \%18.8 kültür, \%40.4'ü yerli ve \%58.4'ü melez ırklardan oluşmaktadır. İşletmelerin \%12.9'u yerli, \%23.4'ü melez ve \%63.7'si kültür ırkını tercih etmiştir. Kültür ırkı içinde ise en fazla \%72.4 Simental ırkı tercih edilirken, bunu \%14.3 oranıyla Siyah Alaca ve \%13.4 oranıyla Esmer ırk izlemiştir. İşletmelerde ırk tercihine işletmecilerin eğitim durumu, yaşı, hayvancılık yaptığı süre, hayvancılık yapma ve sürdürme nedeni, işletmelerin tipi, mevcut hayvan varlığı ve ırkı etkili olmuştur. Buna göre, okuryazar olmayan işletmeciler \%17.4 yerli ve \%60.9 kültür ırkını tercih ederken, eğitimi lise olanlarda yerli ırk tercihi \%4.2 olurken, kültür ırkı tercihi \%70.8'e yükselmiştir. Yerli ırk tercihinin yaşlı işletmecilerde genç işletmecilerden daha fazla olduğu belirlenmiştir. Yerli ve melez irklarının hayvan sayısı az olan işletmelerde, çok olan işletmelere oranla daha fazla tercih edildiği belirlenmiştir. Yerli ırkı olan işletmelerin \%29.6 oranında kültür ırkını tercih ederken, \%43.7 oranında tekrar yerli ırk tercih etmeleri dikkat çekici bulunmuştur. Sonuç olarak, işletmelerin ırk tercihinde yetiştirilen mevcut ırkın, işletmecilerin yaşı ve eğitim durumu gibi faktörler önemli rol oynamıştır. Yerli ırkı olan işletmecilerin tekrar yüksek oranda yerli ırkı tercih etmeleri anlamlı bulunmuştur. Bununla birlikte, işletmelerin sahip olduğu hayvan varlığı, ahır durumu ve teknik imkanlar ile işletmecilerin bilgi ve tecrübeleri kültür ırkı tercihinde önemli rol oynamıştır.

\section{Breed Preference and Affecting Factors in Dairy Cattle Farms. The Case of Siirt Province}

\section{ABSTRACT}

The aim of this study was to determine breed preference and affecting factors in dairy cattle farms. For this purpose, 250 enterprises were surveyed in Siirt province and the data were analyzed with SPSS 21.0 and cross tables were created. Overall, $40.4 \%$ of the existing cattle in the farm consists of domestic, $18.8 \%$ culture and $58.4 \%$ hybrid breeds. Generally, $12.9 \%$ of farm preferred domestic, $23.4 \%$ preferred hybrid and $63.7 \%$ preferred culture breeds. Simultaneous breed was preferred at the most in the culture breed with $72.4 \%$, followed by Holstein with $14.3 \%$ and Brown Swiss with $13.4 \%$. The breed preference in the farms was influenced by the educational status, age, time of livestock breeding, the reason for making livestock, maintaining livestock and satisfaction with livestock breeding, the type of farms, the presence of animals and the breed of the existing animals. Based on these results, while illiterate farmers preferred $17.4 \%$ native and $60.9 \%$ cultural breeds, the high school graduates favored $4.2 \%$ native and up to $70.8 \%$ culture breeds. It is determined that the preference of the domestic breed is higher in the elderly operators than the young ones. It was concluded that

\section{Araştırma Makalesi}

\author{
Makale Tarihçesi \\ Geliş Tarihi : 03.01.2020
}

Kabul Tarihi : 18.04 .2020

\section{Anahtar Kelimeler}

Irk tercihi

Süt sığırcılığ

Siirt

\section{Research Article}

$\begin{array}{ll}\text { Article History } & \\ \text { Received } & : 03.01 .2020 \\ \text { Accepted } & : 18.04 .2020\end{array}$

\section{Keywords \\ Breed preference \\ Dairy Cattle}

Siirt 
the number of animals of the domestic and crossbreed breeds were more preferred than the farms in the enterprises with low number of animals. It was noteworthy that only $29.6 \%$ of the farms with (Domestic) breed preferred culture, while $43.7 \%$ preferred (Domestic) breed again. As a result, the factors such as the age and education level of the existing breeds, the operators, and the education level they have raised in the breed preference of the farms played an important role. It was found meaningful that the operators of the (Domestic) breeds preferred the same breed again. However, the animal existence, barn condition and technical facilities of the farms and the knowledge and experience of the operators have played an important role in the choice of culture breeds.

To Cite : Bakır G, Ören MY 2020. Süt Sığırcılığı İşletmelerinde Irk Tercihi ve Etkileyen Faktörler: Siirt İli Örneği. KSÜ Tarım ve Doğa Derg 23 (5): 1393-1405. DOI: 10.18016/ksutarimdoga.vi.666342.

\section{GİRIŞ}

Türkiye'de süt sığgrcılığı, son yıllarda hem yapısal yönden hem de üretim miktarı ve kalite yönünden önemli yapısal değişiklikler ve gelişmeler göstermiştir. Bir üretim sektörü olarak, yeterli düzeyde olmasa da, farklı tarım politikası araçları ile zaman zaman önemli şekilde desteklenmiştir. Türkiye'de farklı illerdeki sığırcılık işletmelerinin yapısal durumlarinı ve irk tercihlerini belirlemeye yönelik olarak daha önceki yıllarda yapılmış çalışmalar bulunmaktadır. Bu tip çalışmaların daha yaygın bir şekilde ve belirli aralıklarla tekrarlanması, alandaki verilerin güncellenmesi, sektördeki mevcut durumun tespiti, zaman içerisindeki değişimlerin takip edilebilmesi ve sorunlara çözümler üretilebilmesi yanında geleceğe yönelik gerçekçi planlamaların yapılabilmesi için de önem arz etmektedir (Bakır, 2002a; Bakır, 2002b; Tugay ve Bakır, 2006; Tugay ve Bakır, 2008; Kaygisız ve ark. 2008; Tugay ve Bakır, 2009; Han ve Bakır, 2009; Şeker ve ark., 2012; Ünalan ve ark., 2013; Bakan ve Aydın, 2016; Güler ve ark., 2016; Koçyiğit ve ark., 2017).

Han ve Bakır (2009)'ın Diyarbakır ili Ergani ilçesindeki işletmelerde yapmış olduğu çalışmada, işletmecilerin melez ırkları tercih ettiğini ve melez ırkı tercih etme oranının eğitim seviyesiyle önemli derecede pozitif ilişkili olduğunu belirlemişlerdir. Aynı araştırmacılar, işletmecilerin deneyimleri ile ırk tercihleri arasında da farklı ilişkiler tespit etmekle birlikte, tüm deneyim gruplarında melez ırk tercihinin ön plana çıktığını ve bununla beraber yerli ırklarında tercih edildiğini bildirmektedirler. Araştırmacılar, işletmecilerin yetersiz bakım ve besleme şartlarına, hastalıklara dayanıklı olması ve uzun mesafe yürümeye dayanıklı olması sebebiyle yerli ırkları tercih ettiklerini de vurgulamaktadırlar.

Tugay ve Bakır (2006)'ın Giresun yöresindeki yapmış olduğu çalışmada işletmelerde çoğunlukla kültür ve melez ırkların tercih edildiğini; kültür ırkları içerisinde de önem sırasına göre, Jersey, Esmer ve Siyah Alaca ırklarının daha çok tercih edildiğini bildirmektedirler. Araştırmacılar, işletmecilerin ırk tercihi yaparken irkın veriminin yüksek olmasına, bakımının kolay olmasına ve ürünlerinin pazarda yer bulması gibi hususlara dikkat ettiklerini tespit etmişlerdir.

Bakır ve Kibar (2019) tarafından Muş ilinde yapılan araştırmada, işletmelerin \%4'ünün yerli, \%26.9'unun melez ve \%69.1'inin kültür ırkını tercih ettiklerini ve kültür ırkları arasında Simental ırkının ilk sırada (\%74.9) yer aldığını, bunu \%15 oranıyla Esmer ırkının izlediğini tespit etmişlerdir. İşletmelerde $r$ rk tercihinde mevki, hayvan sayısı, işletme tipi ve ırkın etkisi önemli bulunmuştur. Issletmelerde hayvan sayısı artarken, kültür ırkı tercihi düşmekte ve melez ırk tercihinde artış görülmektedir. Eğitim düzeyi arttıkça kültür ırkı içerisinde Simental tercihi azalırken, Esmer tercihi yükselmiştir. Süt tipi işletmelerde kültür ırkı tercih oranı \%73.2 iken, kombine tipi işletmelerde bu oran \%65.2 olarak tespit edilmiştir. Hayvancılıktan memnun olan ve işi sürdürmek isteyen işletmelerin irk tercihi en çok kültür ve melez olurken, kültür ırkı içerisinde de Simental en fazla (\%76.4) tercih edilen irk olduğu bildirilmektedir.

Yukarıda verilen çalışmalardan da görüldüğü üzere, işletmecilerin irk tercihini etkileyen birçok faktörün olduğu anlaşılmaktadır. Bu çalışma, Siirt ilinde bulunan süt sığırcılığı işletmelerinde irk tercihleri ve urk tercihini etkileyen faktörlerin belirlenmesi amacıyla yapılmıştır.

\section{MATERYAL ve METOT}

Araştırma materyalini, Siirt Il Tarım ve Orman Müdürlüğü kayıtlarından elde edilen işletme sayısı dikkate alınarak, il merkezi ile Tillo, Kurtalan, Baykan, Şirvan, Pervari ve Eruh olmak üzere 6 ilçede bulunan işletmelerden şansa bağlı olarak seçilen 250 işletmede 2019 yılı Şubat ve Mart ayında yapılan anketlerden elde edilen orijinal veriler oluşturmuştur. Anket soruları yazarlar tarafından geliştirilmiştir. Türkvet kaydında hayvan sayısı bir ve iki olarak görülen ancak varlığı şüpheli olan 
işletmelerin bir kısmı (işletmelerin yaklaşık \%50'si) ankete dâhil edilmemiştir. Anket çalışmalarında örnek hacminin en az \%3 (Yamane, 2006) veya \%10'un (Cochran, 1977; Arıkan, 2000) alınması yeterli olacağı bildirilmiştir. Basit tesadüfi örnekleme metodu ile belirlenen örnek sayısı daha az olduğundan, örnek hacminin birim sayısı arttıkça ana kitleyi daha iyi temsil etme yeteneğini yükselteceği için (Sümbüloğlu ve Sümbüloğlu, 2007) bu çalışmada örnek hacmi \%3.3 olarak belirlenmiştir. İşletmelerde; işletmecilerin eğitim durumu, yaşı, hayvancılık yaptığı süre, hayvancılık yapma ve sürdürme nedeni, işletmelerin tipi, mevcut hayvan varlığı ve mevcut ırkı" ırk tercihini etkileyen faktörler olarak ele alınmıştır. Elde edilen verilerin SPSS 21.0 paket programı kullanılarak çapraz tabloları yapılmış ve faktör özellik arasındaki ilişkiler khi-kare analizi ile tespit edilmiştir (Düzgüneş ve ark., 1983).

\section{BULGULAR ve TARTIŞMA}

Anketin yapıldığı dönemde işletmelerde en çok (\%40.8) melez irk sığırların yetiştirildiği tespit edilmiştir (Çizelge 1). Bunu, \%28.8 oranıyla yerli ırk ve $\% 12.8$ oranıyla kültür ırkı sığırlar izlemektedir. Benzer araştırmalarda, işletmelerde yetiştirilen ırkları, Ildız (1999) Tokat ilindeki sığır varlığının çoğunluğunu Esmer ırkın (\%55.23) oluşturduğunu; Bakır (2002b) Van ilindeki işletmelerdeki mevcut sığırların \%61.1'ini Sarı Alaca, \%33.5'ini Siyah Alaca ve \%5.4'ünü Esmer irkın oluşturduğunu; Yılmaz ve ark. (2003)'i Hatay ilinde melez irkların oranının (\%43.3) diğer irklardan yüksek olduğunu; Şeker ve ark., (2012)'ı Muş ilinde işletmelerdeki hayvanların \%46.9'unun yerli, \%37.2'sinin melez ve \%15.9'unun kültür ırkı olduğunu ve kültür ırkı sığırların ise \%70.3'ünün Esmer, \%17.2'sinin Simental ve \%12.5'inin Siyah Alaca irkından meydana geldiğini; Daş ve ark. (2014)'ı Bingöl ilinde melez, kültür ve yerli ırk şeklinde sıralandığını; Bakır ve Kibar (2019) Muş ilinde işletmelerde en fazla \%38.4 oranıly melez ırk yer aldığını, bunu \%24 oranıyla yerli+melez ırkların izlediğini bildirmişlerdir.

Öztürk (2009) Mardin ilinde yaptığı araştırmada, işletmelerde mevcut sığır ırkları içerisinde en çok yetiştirilen ırkın Siyah Alaca (\%44.3) olduğunu, bunu Simental (\%20.13), Yerli (\%38.58) ve Esmer rrkı sığırıların (\%4.97) izlediğini bildirmektedir. Erzincan iline bağlı Çayırlı ilçesinin sığırcılık işletmelerinde Esmer (\%45.4) ile Sarı Alacanın (\%47.8) hakim kültür ırkı olarak yetiştirildiğini ve Siyah Alaca ırkının daha az tercih edildiği bildirilmektedir (Özyürek ve ark., 2014).

$\mathrm{Bu}$ araştırmada bulunan sonuç ile Bingöl ve Muş ile Hatay ilinde yapılan araştırmada bulunan sonuçlarla benzerlik göstermektedir. Ancak, Tokat ilinde Esmer, Muş ilinde (Şeker ve ark., 2012) yerli ırkın yoğun yetiştirilmesi, bu araştırma sonuçlarıyla farklılık göstermektedir. Bu araştırmanın yapıldığı Siirt ilinin de yer aldığı Bingöl ve Muş gibi Doğu illerinde melez ırkın ön plana çıktığı ve ülkenin iç bölgesinde yer alan Tokat ilinde ise kültür ırkının yetiştirildiği belirlenmiştir. Ancak, ülkenin Doğusunda yer alan Muş ilinde ise yerli ırkın ön plana çıkması, araştırmanın yapıldığ 1 yıllara mahsus olduğu, aynı ilde daha sonra yapılan araştırmada melez irkın yetiştirildiği edildiği tespit edilmiştir.

İşletmecilerin mevcut yetiştirdikleri ırkın dışında en çok tercih ettikleri ırk \%63.7 oranıyla kültür ırkı olmuştur. Bunu sirasıyla, melez (\%23.4) ve yerli (\%12.9) Irklar takip etmiştir (Çizelge 1). İşletmelerde kültür ırkları arasında da Simental ırkı en çok tercih (\%72.4) edilirken, Esmer ve Siyah Alaca rrkları ise benzer oranlarda tercih edilmiştir. Yörede bulunan işletmelerin barınak yapıları ve bakım besleme şartlarının yetersiz olması ile işletmelerde bulunan ortalama hayvan sayısının az olması dikkate alındığında, en çok melez ırkın yetiştirilmesi anlamlı bulunmuştur. İşletmelerin kültür ırkı melezi ağırlıklı yetiştiricilik yapmalarına rağmen, bir sonraki tercihlerinin saf kültür ırkı ve kültür ırkı arasında da Simental ırkını tercih etmişlerdir. Bu durum, işletmecilerin yetiştiricilik açısından bilinçlendiğini ve süt üretimi yanında besiciliğe de önem verdiklerini göstermektedir.

Van ilinde yapılan araştırmada, işletmelerin \%48.2'sinin Simental, \%26.3'ünün Esmer, \%8.6'sinın Siyah Alaca, \%11.9'unun Simental+Esmer ve \%2.3'ünün Siyah Alaca+Esmer ırkını tercih ettikleri bildirilmektedir (Bakır, 2002). Araştırmacı, genel olarak il merkezinde Simental ırkının, ilçelerde ise Esmer ırkının tercih edilmesine rağmen, dağıtılan Simental ırkı gebe düvelerin doğum yapmaması, ineklerin ölmesi ve kısır kalması nedenleriyle, işletmelerin Simental yerine Esmer irka yönelmelerine neden olduğunu bildirmektedir. Ayrıca, ilde bazı işletmelerin hiçbir kültür ırkını istememelerini, barınak sartlarının yetersiz ve bakım besleme imkânlarının kıt olmasından kaynaklandığını bildirmektedir.

Giresun yöresinde yapılan araştırmada, işletmelerin \%1.6'sının yerli, \%25.2'sinin melez \%73.2'sinin kültür ırkını tercih ettikleri ve kültür ırkını tercih eden işletmelerin \%7'sinin simental, \%21.4'ünün Siyah Alaca, \%32.4'ünün Esmer, \%39.1'inin Jersey ırkına karar verdikleri bildirilmiştir. Kültür ırkını tercih eden işletmecilerin, veriminin yüksek olmasını belirtmeleri, işletmecilerin tercih ettikleri kültür ırkını tanıdıkları ve bu konuda bilinçli olduklarının işareti sayıldığı bildirilmektedir (Tugay ve Bakır, 2006). Han ve Bakır (2009) Diyarbakır ili Ergani ilçesinde yapmış olduğu çalışmada işletmelerde melez ırkların tercih edildiğini bildirmişlerdir. Araştırıcılar, bazı işletmecilerin yetersiz bakım ve besleme şartlarına, hastalıklara ve uzun yürümeye dayanıklı 
olması sebebiyle de yerli irkları tercih ettiklerini bildirmişlerdir. Muş ilinde Şeker ve ark., (2012)'ı tarafindan yapılan araştırmada, Esmer ve Simental ırklarını tercih sebeplerini; yetiştirme şartlarının uygun olması (\%37.5), veriminin yüksek olması (\%35.4) ve alışkanlık (\%3.1) şeklinde bildirmiştir. Bununla birlikte, sığır yetiştiriciliği yapan kişilerin özellikle kombine verimli irkları tercih etmelerinin bir başka nedenini, bölgenin sığır besiciliği açısından önemli bir merkez olması dolayısıyla, besi materyali olarak bu irkların performanslarından duyulan memnuniyet olarak bildirilmektedir. Savaş ve Yenice (2016), Rize ilindeki işletmelerde çoğunlukla Jersey ırkının tercih edildiğini, Montofon ve Holştayn ırklarının ise az sayıda bulunduğunu bildirmektedir.

Bakır ve Kibar (2019)'ın Muş ilinde yaptıkları diğer bir araştırmada, işletmelerin \%69.1'inin kültür, \%26.9'unun melez ve \%4'ünün yerli ırkını tercih ettikleri bildirilmektedir. Kültür ırkı tercihinde ise Simental ırkı \%74.9 oranıyla ilk sırada yer alırken, bunu \%15 oranıla Esmer ırkı izlemiştir. İşletmecilerin yerli ırkı bırakıp kültür ırkına doğru yönelmeleri, işletmecilerin hem hayvanların verim miktarına önem verdiklerini hem de bu işten geçim sağladıklarını ve geliştirmek istediklerini göstermektedir. İşletmecilerin kültür ırkı melezini tercih ederken, yetiştirme şartlarını ve işletme imkanlarının kültür ırkı için uygun olmadığını dikkate aldıklarını bildirmektedir.

Tercih edilen ırk bazında Van, Giresun ve Muş ilinde bulunan sonuçlar ile bu araştırmada bulunan sonuç benzerlik göstermektedir. Kültür ırkı arasında tercih noktasında Giresun ilinde Jersey ırkı ön plana çıkmış ve bu araştırma bulgusuyla farklılık gösterirken, Van ve Muş ilinde ise ilk planda Simental daha sonra Esmer ırkının ön plana çıkması bu araştırma bulgusuyla benzerlik göstermektedir.

Mevki bazında işletmelerin mevcut irk dağılımına bakıldığında, Baykan ve Pervari ilçelerinde yerli ırk, merkez, Tillo ve Eruh ilçelerinde ise melez urk yoğunluklu yetiştiricilik yapılmaktadır. Kurtalan ilçesinde işletmelerde yerli ırkın bulunmaması dikkat çekici bulunmuştur. İşletmelerinde yerli irk bulunmayan Kurtalan ilçesinde, işletmelerin \%94.4'ünün yine kültür ırkını tercih etmesi dikkat çekici bulunmuştur. Diğer ilçelerden Merkez ve Tillo'daki işletmelerin ağırlıklı olarak kültür ırkını tercih ederken, diğer ilçeler melez ve kültür ırkı ağırlıklı tercih yapmışlardır. Kurtalan, Şirvan ve Baykan ilçelerindeki işletmeler kültür ırkları arasından yüksek oranlarda Simental ırkını tercih etmişlerdir. Eruh ilçesindeki işletmelerin diğer ilçelerden farklı bir oranda (\%71.4) Siyah Alaca ırkını tercih etmeleri dikkat çekici bulunmuştur.

Eğitim düzeyi okuryazar olmayan işletmeciler ağırlıklı olarak yerli ve melez ırk yetiştirirken, ırk tercihinde $\% 60.9$ oranında kültür ırkını tercih etmişlerdir (Çizelge 2). Kültür ırkları arasından tercih de ise Simental ırkı ilk sırada yer alırken, bunu benzer oranlarda tercih edilen Esmer ve Siyah Alaca ırkları izlemiştir. Eğitimi lise olan yetiştiricilerin işletmelerinde \%56 oranında melez irk bulunurken, ırk tercihinde ise $\% 70.8$ oranında kültür ırkını ve $\% 25$ oranında da melez ırkını tercih etmişlerdir. İşletmecilerin eğitim düzeyi yetiştirilen rrk ve $1 r k$ tercihi arasındaki ilişki $(\mathrm{p}<0.05)$ önemli bulunmuştur. Eğitim düzeyi artarken, işletmede yetiştirilen ırklar arasında yerli ırkın oranı düşmekte, tercih edilen ırklar arasında kültür ırkının oranı da önemli derecede artmaktadır. Ayrıca, kültür ırkları arasından tercih de eğitim düzeyi okuryazar olmayanlar simental ırkı yanında benzer oranlarda esmer ve siyah alaca ırkını da tercih ederken, eğitim düzeyi lise olanlarda ise simental tercihi önemli oranda yükseliş göstermiştir. $\mathrm{Bu}$ durum, eğitim düzeyi lise olan işletmecilerin daha profesyonel davrandıklarını ve ticari yönlü yetiştiricilik yaptıklarının bir göstergesi olarak düşünülmektedir.

Han ve Bakır (2009) Diyarbakır ili Ergani ilçesinde yapmış oldukları çalışmada işletmecilerin melez ırkı tercih etme oranının eğitim seviyesiyle önemli derecede ilişkili olduğunu bildirmişlerdir. Buna göre, eğitim düzeyi okuryazar olan ve olmayan işletmeciler yerli ırkı tercih ederken (\%48.5), eğitim seviyesi arttıkça melez ırka doğru bir yöneliş olduğu ve buna ait değerlerin ilkokuldan, lise ve üzerine kadar (\%52.6, \%75.0 ve \%92.3) artan bir eğilim izlediği belirtilmiştir. Muş ilinde yapılan araştırmada ise, eğitim durumunun ırk tercihini önemli şekilde etkilediği ve okuryazar olmayan işletmecilerin rrk tercihini ağırlıklı olarak kültür (\%52) ve melez ırk (\%36) şeklinde belirlediği bildirilmektedir (Bakır ve Kibar, 2019). Kültür ırkları arasından da en fazla (\%95.2) Simental ırkının okuryazar olmayan işletmelerde tespit edildiği ve eğitim düzeyi arttıkça Simental ırkı tercihinin azaldığı, buna karşın esmer ırkı tercihinin ise yükseldiği bildirilmektedir. Her iki araştırma sonuçlarından, eğitim düzeyinin ırk seçiminde önemli rol oynadığ $\breve{g}_{1}$ ve bu bulguların araştırmamı sonuçlarıyla uyumlu olduğu belirlenmiştir. Irk seçiminde eğitim düzeyinin önemli etkisinin olduğu bildirildiği diğer araştırma sonuçlarıyla bu araştırma sonucu arasında ciddi benzerlikler bulunmuştur. $\mathrm{Bu}$ araştırmada eğitim düzeyi okuryazar olmayan yetiştiriciler yerli rrkın yanında melez ırkı da tercih ederken, Ergani'deki okuryazar olmayan yetiştiriciler sadece yerli rrkı tercih etmişlerdir. Muş ilinde yapılan araştırmada ise bu araştırma sonucuna benzer olarak okuryazar olmayan yetiştiriciler kültür ırkını ve kültür ırkları arasından da Simental ırkını tercih etmişlerdir.

Yaşı 30'un altında olan yetiştiricilerin işletmelerinde yerli ve melez irk bulunurken, irk tercihinde \%63.6 oranında kültür ırkını tercih etmişledir (Çizelge 3). 
Çizelge 1. İşletmelerin mevcut ırkı ve ırk tercihinin mevkiye göre değişimi

Table 1. The change of current breed and breed preference of farms according to the location of farms

\begin{tabular}{|c|c|c|c|c|c|c|c|c|c|c|c|c|c|c|c|}
\hline \multirow{2}{*}{\multicolumn{2}{|c|}{$\begin{array}{l}\text { İşletmenin } \\
\text { mevki } \\
\text { (Location of } \\
\text { farm) }\end{array}$}} & \multicolumn{5}{|c|}{ Mevcut-(Current breed)** } & \multirow[b]{2}{*}{$\begin{array}{l}\text { Toplam } \\
\text { (Total) }\end{array}$} & \multicolumn{3}{|c|}{ Irk tercihi-(Breed preferrence)*** } & \multirow[b]{2}{*}{$\begin{array}{l}\text { Toplam } \\
\text { (Total) }\end{array}$} & \multicolumn{3}{|c|}{$\begin{array}{l}\text { Kültür ırkı tercihi-(Culture breed } \\
\text { preferrence)*** }\end{array}$} & \multirow[b]{2}{*}{$\begin{array}{l}\text { Toplam } \\
\text { (Total) }\end{array}$} \\
\hline & & $\begin{array}{c}\text { Yerli } \\
\left(\text { Domestic) }{ }^{1}\right.\end{array}$ & $\begin{array}{l}\text { Kültür } \\
\text { (Culture) }\end{array}$ & $\begin{array}{c}\text { Melez } \\
\text { (Crossbreed })^{3}\end{array}$ & $\begin{array}{l}\text { Yerli+Melez } \\
\quad(1+3)\end{array}$ & $\begin{array}{c}\text { Kültür } \\
+ \text { Melez } \\
(2+3)\end{array}$ & & $\begin{array}{c}\text { Yerli } \\
\text { (Domestic) }\end{array}$ & $\begin{array}{l}\text { Kültür } \\
\text { (Culture) }\end{array}$ & $\begin{array}{c}\text { Melez } \\
\text { (Crossbreed) }\end{array}$ & & $\begin{array}{c}\text { Esmer } \\
\text { (B.SwiSS })\end{array}$ & $\begin{array}{c}\text { Simental } \\
\text { (Simmental) }\end{array}$ & $\begin{array}{l}\text { S. Alaca } \\
\text { (Holstein) }\end{array}$ & \\
\hline \multirow{2}{*}{ Merkez } & Adet & 6 & 5 & 24 & 6 & 2 & 43 & 3 & 34 & 6 & 43 & 11 & 23 & 7 & 41 \\
\hline & $\%$ & 14 & 11.6 & 55.8 & 14 & 4.7 & 100 & 7 & 79.1 & 14 & 100 & 26.8 & 56.1 & 17.1 & 100 \\
\hline \multirow{2}{*}{ Kurtalan } & Adet & - & 16 & 19 & 7 & 12 & 54 & - & 51 & 3 & 54 & - & 50 & 4 & 54 \\
\hline & $\%$ & - & 29.6 & 35.2 & 13 & 22.2 & 100 & - & 94.4 & 5.6 & 100 & - & 92.6 & 7.4 & 100 \\
\hline \multirow{2}{*}{ Şirvan } & Adet & 12 & 4 & 16 & 6 & - & 38 & 5 & 26 & 6 & 37 & 2 & 29 & 1 & 32 \\
\hline & $\%$ & 31.6 & 10.5 & 42.1 & 15.8 & - & 100 & 13.5 & 70.3 & 16.2 & 100 & 6.3 & 90.6 & 3.1 & 100 \\
\hline \multirow{2}{*}{ Pervari } & Adet & 29 & 1 & 15 & 2 & - & 47 & 12 & 21 & 14 & 47 & 9 & 21 & 6 & 36 \\
\hline & $\%$ & 61.7 & 2.1 & 31.9 & 4.2 & - & 100 & 25.5 & 44.7 & 29.8 & 100 & 25.0 & 58.3 & 16.7 & 100 \\
\hline \multirow{2}{*}{ Tillo } & Adet & - & 1 & 8 & 1 & - & 10 & - & 6 & 4 & 10 & 3 & 6 & 1 & 10 \\
\hline & $\%$ & - & 10 & 80.0 & 10 & - & 100 & - & 60.0 & 40.0 & 100 & 30.0 & 60.0 & 10 & 100 \\
\hline \multirow{2}{*}{ Baykan } & Adet & 25 & 3 & 11 & 4 & 1 & 44 & 12 & 17 & 14 & 43 & 3 & 25 & 2 & 30 \\
\hline & $\%$ & 56.8 & 6.8 & 25 & 9.1 & 2.3 & 100 & 27.9 & 39.5 & 32.6 & 100 & 10 & 83.3 & 6.7 & 100 \\
\hline \multirow{2}{*}{ Eruh } & Adet & - & 2 & 9 & 3 & - & 14 & - & 3 & 11 & 14 & 1 & 3 & 10 & 14 \\
\hline & $\%$ & - & 14.3 & 64.3 & 21.4 & - & 100 & - & 21.4 & 78.6 & 100 & 7.1 & 21.4 & 71.4 & 100 \\
\hline \multirow{2}{*}{$\begin{array}{l}\text { Toplam } \\
\text { (Total) }\end{array}$} & Adet & 72 & 32 & 102 & 29 & 15 & 250 & 32 & 158 & 58 & 248 & 29 & 157 & 31 & 217 \\
\hline & $\%$ & 28.8 & 12.8 & 40.8 & 11.6 & 6 & 100 & 12.9 & 63.7 & 23.4 & 100 & 13.4 & 72.4 & 14.3 & 100 \\
\hline
\end{tabular}

$* * \mathrm{p}<0.01$

Çizelge 2. İşletmelerin mevcut ırkı ve ırk tercihinin eğitim durumuna göre değişimi

Table 2. The change of current breed and breed preference of farms according to the education of farmers

\begin{tabular}{|c|c|c|c|c|c|c|c|c|c|c|c|c|c|c|c|}
\hline \multirow{2}{*}{\multicolumn{2}{|c|}{$\begin{array}{l}\text { Eğitim durumu } \\
\text { (Education statu) }\end{array}$}} & \multicolumn{5}{|c|}{ Mevcut-(Current breed) } & \multirow[b]{2}{*}{$\begin{array}{r}\text { Toplam } \\
\text { (Total) }\end{array}$} & \multicolumn{3}{|c|}{ Irk tercihi-(Breed preferrence) } & \multirow[b]{2}{*}{$\begin{array}{l}\text { Toplam } \\
\text { (Total) }\end{array}$} & \multicolumn{3}{|c|}{$\begin{array}{c}\text { Kültür ırkı tercihi-(Culture breed } \\
\text { preferrence) }\end{array}$} & \multirow[b]{2}{*}{$\begin{array}{l}\text { Toplam } \\
\text { (Total) }\end{array}$} \\
\hline & & $\begin{array}{c}\text { Yerli } \\
\left({\text { Domestic })^{1}}^{-}\right.\end{array}$ & $\begin{array}{c}\text { Kültür } \\
\text { (Culture) }\end{array}$ & $\begin{array}{c}\text { Melez } \\
\text { (Crossbreed }^{\beta}\end{array}$ & $\begin{array}{c}\text { Yerli+Melez } \\
(1+3)\end{array}$ & $\begin{array}{c}\text { Kültür+Melez } \\
(2+3)\end{array}$ & & $\begin{array}{c}\text { Yerli } \\
\text { (Domestic) }\end{array}$ & $\begin{array}{c}\text { Kültür } \\
\text { (Culture) }\end{array}$ & $\begin{array}{c}\text { Melez } \\
\text { (Crossbreed) }\end{array}$ & & $\begin{array}{c}\text { Esmer } \\
\text { (B.Swiss) }\end{array}$ & $\begin{array}{c}\text { Simental } \\
\text { (Simmental) }\end{array}$ & $\begin{array}{l}\text { S. Alaca } \\
\text { (Holstein) }\end{array}$ & \\
\hline \multirow{8}{*}{$\begin{array}{l}\text { Okuryazar } \\
\text { değil } \\
\text { (illiterate) } \\
\text { Ilkokul } \\
\text { (Primary } \\
\text { school) } \\
\text { Ortaokul } \\
\text { (Secondary } \\
\text { school) } \\
\text { Lise } \\
\text { (High } \\
\text { school) }\end{array}$} & Adet & 14 & 7 & 19 & 5 & 1 & 46 & 8 & 28 & 10 & 46 & 10 & 22 & 9 & 41 \\
\hline & $\%$ & 30.4 & 15.2 & 41.3 & 10.9 & 2.2 & 100 & 17.4 & 60.9 & 21.7 & 100 & 24.4 & 53.7 & 22 & 100 \\
\hline & Adet & 36 & 16 & 49 & 19 & 10 & 130 & 15 & 82 & 32 & 129 & 11 & 81 & 19 & 111 \\
\hline & $\%$ & 27.7 & 12.3 & 37.7 & 14.6 & 7.7 & 100 & 11.6 & 63.6 & 24.8 & 100 & 9.9 & 73 & 17.1 & 100 \\
\hline & Adet & 16 & 6 & 20 & 4 & 3 & 49 & 8 & 31 & 10 & 49 & 5 & 35 & 2 & 42 \\
\hline & $\%$ & 32.7 & 12.2 & 40.8 & 8.2 & 6.1 & 100 & 16.3 & 63.3 & 20.4 & 100 & 11.9 & 83.3 & 4.8 & 100 \\
\hline & Adet & 6 & 3 & 14 & 1 & 1 & 25 & 1 & 17 & 6 & 24 & 3 & 19 & 1 & 23 \\
\hline & $\%$ & 24 & 12 & 56 & 4 & 4 & 100 & 4.2 & 70.8 & 25 & 100 & 13 & 82.6 & 4.3 & 100 \\
\hline \multirow{2}{*}{$\begin{array}{l}\text { Toplam } \\
\text { (Total) }\end{array}$} & Adet & 72 & 32 & 102 & 29 & 15 & 250 & 32 & 158 & 58 & 248 & 29 & 157 & 31 & 217 \\
\hline & $\%$ & 28.8 & 12.8 & 40.8 & 11.6 & 6 & 100 & 12.9 & 63.7 & 23.4 & 100 & 13.4 & 72.4 & 14.3 & 100 \\
\hline
\end{tabular}

$* \mathrm{p}<0.05$ 
Cizelge 3. İşletmelerin mevcut ırkı ve ırk tercihinin işletmecilerin yaşına göre değişimi

Table 3. The change of current breed and breed preference of farms according to the age of farmers

\begin{tabular}{|c|c|c|c|c|c|c|c|c|c|c|c|c|c|c|c|}
\hline & & \multicolumn{5}{|c|}{ Mevcut-(Current breed) } & \multirow[b]{2}{*}{$\begin{array}{r}\text { Toplam } \\
\text { (Total) }\end{array}$} & \multicolumn{3}{|c|}{ Irk tercihi-(Breed preferrence) } & \multirow[b]{2}{*}{$\begin{array}{r}\text { Toplam } \\
\text { (Total) }\end{array}$} & \multicolumn{3}{|c|}{$\begin{array}{c}\text { Kültür ırkı tercihi-(Culture breed } \\
\text { preferrence) }\end{array}$} & \multirow[b]{2}{*}{$\begin{array}{r}\text { Toplam } \\
\text { (Total) }\end{array}$} \\
\hline \multicolumn{2}{|c|}{$\begin{array}{l}\text { Yaş (Age of } \\
\text { farmer) }\end{array}$} & $\begin{array}{c}\text { Yerli } \\
(\text { Domestic) }\end{array}$ & $\begin{array}{l}\text { Kültür } \\
\text { (Culture) }\end{array}$ & $\begin{array}{c}\text { Melez } \\
\text { (Crossbreed) }\end{array}$ & $\begin{array}{l}\text { Yerli+Melez } \\
\quad(1+3)\end{array}$ & $\begin{array}{c}\text { Kültür } \\
+ \text { Melez } \\
(2+3)\end{array}$ & & $\begin{array}{r}\text { Yerli } \\
\text { (Domestic) }\end{array}$ & $\begin{array}{r}\text { Kültür } \\
\text { (Culture) }\end{array}$ & $\begin{array}{r}\text { Melez } \\
\text { (Crossbreed) }\end{array}$ & & $\begin{array}{c}\text { Esmer } \\
(\text { B.SWisS })\end{array}$ & $\begin{array}{l}\text { Simental } \\
\text { (Simmental) }\end{array}$ & $\begin{array}{l}\text { S. Alaca } \\
\text { (Holstein) }\end{array}$ & \\
\hline \multirow{2}{*}{$30>$} & Adet & 9 & 5 & 7 & 0 & 1 & 22 & 3 & 14 & 5 & 22 & 3 & 16 & 2 & 21 \\
\hline & $\%$ & 40.9 & 22.7 & 31.8 & 0 & 4.5 & 100 & 13.6 & 63.6 & 22.7 & 100 & 14.3 & 76.2 & 9.5 & 100 \\
\hline \multirow{2}{*}{ 30-39 } & Adet & 16 & 4 & 28 & 9 & 3 & 60 & 8 & 34 & 17 & 59 & 8 & 37 & 6 & 51 \\
\hline & $\%$ & 26.7 & 6.7 & 46.7 & 15 & 5 & 100 & 13.6 & 57.6 & 28.8 & 100 & 15.7 & 72.5 & 11.8 & 100 \\
\hline \multirow{2}{*}{$40-49$} & Adet & 23 & 15 & 37 & 12 & 5 & 92 & 6 & 67 & 18 & 91 & 6 & 65 & 12 & 83 \\
\hline & $\%$ & 25 & 16.3 & 40.2 & 13.1 & 5.4 & 100 & 6.6 & 73.6 & 19.8 & 100 & 7.2 & 78.3 & 14.5 & 100 \\
\hline \multirow{2}{*}{$50 \leq$} & Adet & 24 & 8 & 30 & 8 & 6 & 76 & 15 & 43 & 18 & 76 & 12 & 39 & 11 & 62 \\
\hline & $\%$ & 31.6 & 10.5 & 39.5 & 10.5 & 7.9 & 100 & 19.7 & 56.6 & 23.7 & 100 & 19.4 & 62.9 & 17.7 & 100 \\
\hline \multirow{2}{*}{$\begin{array}{l}\text { Toplam } \\
\text { (Total) }\end{array}$} & Adet & 72 & 32 & 102 & 29 & 15 & 250 & 32 & 158 & 58 & 248 & 29 & 157 & 31 & 217 \\
\hline & $\%$ & 28.8 & 12.8 & 40.8 & 11.6 & 6 & 100 & 12.9 & 63.7 & 23.4 & 100 & 13.4 & 72.4 & 14.3 & 100 \\
\hline
\end{tabular}


İşletmeciler kültür ırkları içinden de \%76.2 oranında simental ırkını ve az miktarda da esmer ve siyah alaca ırklarını tercih etmişlerdir. İşletmecilerin yaşı ilerledikçe kültür ırkı tercihi göreceli olarak gerilerken, yerli ve melez ırkı tercihi artış göstermiştir. İşletmecilerin yaşının artmasına bağlı olarak kültür ırkı tercihinde belirlenen düşüş ve yerli ile melez ırklarındaki artış, işletmecilerin risk almaktan sakındıklarını, ticari üretime yönelik değil de geçime yönelik faaliyet gösterdiklerini akla getirmektedir. Ayrıca, işletmecilerin yaşının artmasıyla birlikte işletmelerdeki hayvan sayısında düşüş olması da, yaşlı işletmecilerin ticari üretime yönelik değil de geçime yönelik faaliyet gösterdiklerini işaret etmektedir. Irk seçiminde işletmecilerin yaşının etkisine yönelik bir araştırma bulunmamaktadır.

Hayvancılık yapılan süre $10 \leq$ yıl olan işletmeciler melez ve yerli ırk ağırlıklı yetiştiricilik yaparken, kültür ırkı oranı sadece \%12.2 olarak tespit edilmiştir (Çizelge 4). Hayvancılık yapılan süre arttıkça işletmelerde yerli ve melez ırk mevcudu atış gösterirken, kültür ırkı mevcudunda azalma görülmüştür. Hayvancılık yaptıkları süre $10 \leq$ yıl olan işletmeciler \%62.9 oranında kültür ırkını tercih etmişlerdir. Bu oran, hayvancıllk yapılan süre 31 yll ve üstü olan işletmecilerde \%59.1'e gerilemiş ve yerli ırk tercihinde anlamlı bir artış belirlenmiştir. Yine bu işletmecilerin diğer işletmecilere göre daha fazla esmer irk tercih ettikleri belirlenmiştir. Hayvancilık yapılan süre ile işletmecilerin yaşı arasında doğrusal bir ilişki olduğu dikkate alınırsa, yaşh işletmeciler için yapılan değerlendirmeler burası için de geçerlidir.

Benzer araştırmalardan, Han ve Bakır (2009)'ın Diyarbakır ili Ergani ilçesinde yapmış olduğu çalışmada, işletmecilerin deneyimleri ile irk tercihleri arasında farklı ilişkiler tespit etmekle birlikte, tüm deneyim gruplarında melez irk tercihinin ön plana çıktığ 1 ve bununla beraber yerli irkların da tercih edildiği bildirilmektedir. Köseman ve Şeker (2016) Malatya ilinde sığırcılık yapan işletmelerde yetiştiricilerin \%14.8'inin 6-10 yll, \%12.2'sinin 11-15 yıl, \%29.6'sının 16-20 yıl, \%39.3'ünün 21 yıl ve üzeri, süredir hayvancılıkla uğraştığını bildirmişlerdir.

Muş ilindeki işletmecilerin hayvancılık yaptıkları süreye bağlı olarak irk tercihinde önemli değişiklik olduğu belirlenmiştir (Bakır ve Kibar, 2019). Buna göre, hayvancılık yapılan süre arttıkça işletmecilerin kültür ırkı tercihinin göreceli olarak azaldığı ve melez ırk tercihlerinin attığ ${ }_{1}$ bildirilmektedir. 10 yıldan az süreyle hayvancılık yapan işletmecilerin kültür 1 rkı tercihi \%80.4 iken, 31+ yıl olan işletmecilerde bu oranın \%71.9'a düştüğü belirlenmiştir. Hayvancılık yapılan süre arttıkça yerli ve melez ırkı tercihinde önemli oranda artış olduğu belirlenmiştir.
Irk seçimi ile işletmecilerin hayvancılık yaptıkları süre arasındaki ilişkinin önemli olduğunu bildirildiği diğer araştırma sonuçlarıyla, bu araştırma sonucu arasında uyum bulunmuştur. $\mathrm{Bu}$ araştırmada, hayvancılık yaptıkları süre $10 \leq$ yıl olan işletmeciler melez ve yerli ırk ağırlıklı yetiştiricilik yaparken, Muş ilindeki yetiştiricilerin bu araştırmanın aksine \%80.4 gibi yüksek bir oranda kültür ırkı tercih ettikleri anlamlı bulunmuştur. Ancak, Muş ilindeki yetiştiricilerde hayvancılık yapılan süre arttıkça bu araştırma sonuçlarına benzer olarak yerli ve melez ırkı tercihinde önemli oranda artış olduğu belirlenmiştir. Ayrıca, her iki araştırma sonucunun aksine, Ergani'de bulunan yetiştiricilerin tamamının süreye bağlı kalmaksızın melez ırkını tercih etmeleri dikkat çekici bulunmuştur.

Süt tipi işletmecilik yapan işletmelerin kültür irkı mevcudu \%15.6 iken, irk tercihinde bu oran \%66'ya yükselmiş ve yerli ırk oranı ise \%12.7'ye gerilemiştir (Çizelge 5). Kombine tipi işletmelerde de süt tipi işletmelere benzer durum belirlenirken, bu işletmelerde kültür ırkı tercihi süt tipi işletmelerden daha düşük bulunmuştur. Kültür ırkları arasında irk tercihinde, hem süt tipi hem de kombine işletmelerde simental ilk sırayı alırken, siyah alaca ırkı süt tipi işletmelerde \%17.6 oranıyla ikinci sırayı yer almakta, kombine tipi işletmelerde ise Siyah Alaca tercih edilmemektedir. $\mathrm{Bu}$ durumun, siyah alaca irkının besi performansının zayıf olmasından kaynaklandığı düşünülmektedir.

Muş ilinde Bakır ve Kibar, (2019) tarafından yapılan araştırmada, süt tipi işletmelerde kültür ırkı tercih oranı \%73.2 iken, kombine tipi işletmelerde bu oran $\% 65.2$ olarak tespit edilmiştir. Yerli rrk tercihinin sadece kombine tipi işletmelerde yapıldığı ve simental ırkının tercih oranı süt tipi işletmelerde \%80.1 iken, kombine tipi işletmelerde \%69.9 olarak bulunmuştur. $\mathrm{Bu}$ durum irk bazında araştırmamızda bulunan sonuçlar ile benzerlik göstermemektedir. Ancak, kültür ırkları arasında tercih de farklılık belirlenmiştir. $\mathrm{Bu}$ araştırmada kombine tipi işletmelerde simental ırkı tercihi ilk sırayı alırken, muş ilinde yapılan araştırmada tercih oranı düşük bulunmuştur.

Hayvan sayısı ile mevcut irk ve irk tercihi arasında önemli ilişki bulunmuştur. İşletmelerde mevcut hayvan sayısı arttıkça yerli ırk sayısında azalış ve kültür ırkı sayısında artış belirlenmiştir (Çizelge 6). Irk tercihinde ise, mevcut hayvan sayısı $2 \leq$ baş olan işletmelerde kültür ırkı tercihi $\% 47.5$ iken, işletmelerdeki hayvan sayısı arttıkça kültür ırkı tercihi \%82.1'e yükselmiştir. Bu durumun işletmelerde hayvan sayısının artmasıyla birlikte entansif ve profesyonel üretimin yapılmasından kaynaklandığı düşünülmektedir. Hayvan sayısı az olan işletmelerin hayvancılığ geçim ve geçime katkı olarak yaptıkları belirlenmiştir. 
Benzer konuda Bakır ve Kibar (2019) tarafindan Muş ilinde yapılan araştırmada, hayvan sayısı 9 baş'dan az olan işletmelerin kültür ırkını tercih ettiği (\%71.6) ve melez ırkını ise en fazla 41 baş ve üzeri hayvana sahip işletmelerin (\%32.2) tercih ettiği tespit edilmiştir. Genel olarak işletmelerde bulunan hayvan sayısına göre, işletmecilerin ırk tercihlerinde de önemli değişiklik gösterdiği bildirilmiştir. Van ilinde Bakır (2002) tarafından yapılan diğer bir araştırmada ise, işletmelerdeki hayvan sayısının yetiştiricilerin rrk tercihinde etkili bir faktör olduğu ve $1-5$ baş kültür ırkı sığırı olan işletmelerde, Siyah Alaca ırkı yanında Simental ve Esmer ırkını da tercih ettikleri bildirilmektedir. Muş ilinde yapılan araştırma hayvan sayısı arttıkça melez ırk tercihi artış gösterirken, bu araştırmada ise tersi bir durum olup, hayvan sayısı arttıkça kültür ırkı tercihi artış göstermiştir. Kültür ırkları arasından seçimde hayvan sayısının etkisinin önemli olduğu bildirilen Van ilinde yapılan araştırma sonucuyla, bu araştırma sonucu arasında ciddi benzerlikler bulunmuştur.

İşletmelerde mevcut irk ile rrk tercihi arasında önemli ilişki bulunmuştur (Çizelge 7). Buna göre, yerli ırk bulunan işletmelerin \%43.7 gibi önemli bir oranı yine yerli ırk tercih etmeleri anlamlı bulunmuştur. Yerli ırk isteyenlerin, ileri yaşlı ve fazla masraf yapmadan elde edilen ile ev geçimine katkı için yapmak isteyen işletmeciler olduğu belirlenmiştir. Melez urka sahip işletmelerin \%73.3 oranında kültür ırkı yanında \%25.7 oranında tekrar melez irk istemeleri, işletmecilerin melez urktan memnun olduklarını düşündürmektedir. Kültür+melez ırk yetiştiren işletmelerin tamamı kültür ırkları içinde simental ırkını tercih ederken, bu oran melez ırkı olan işletmelerde \%67'ye gerilemiştir.

Bu konuda Van ilinde (Bakır, 2002) yapılan benzer araştırmada, Esmer irk bulunan işletmeler tercihlerini ilde \%50, ilçede \%61.5 oranında Esmer yönünde yaptıkları ve yetiştiricilerin Esmer ırktan memnun oldukları bildirilmiştir. İldeki işletmecilerin Simental ırkını, ilçede ise Esmer ırkın tercih etmeleri anlamlı bulunmuş ve Siyah Alaca ırkına karşı isteksizlik olduğu bildirilmiştir.

Muş ilinde yapılan diğer bir araştırmada ise, yerli ırkı bulunan işletmecilerin sadece \%40.7'si kültür ırkını tercih ederken, melez ırkını tercih edenlerin oranının daha yüksek olduğu tespit edilmiştir. Kültür ırkı yetiştiren işletmelerin \%81.8 oranında yine kültür ırkı tercihi olması dikkat çekici bulunmuştur. Melez irk yetiştiren işletmelerin yeniden \%30.6 oranında melez irk tercih etmeleri bu ırktan memnuniyet ve işletme şartlarından kaynaklandığ düşünülmektedir (Bakır ve Kibar, 2019).

Irk seçiminde işletmede yetiştirilen rrk ile tercih edilen ırk arasında önemli ilişkinin olduğu bildirilen diğer araştırma sonuçlarıyla, bu araştırma sonucu arasında ciddi benzerlikler bulunmuştur. Buna göre, Muş ilindeki yerli ırk yetiştiren işletmecilerin önemli bir kısmı yine yerli rrk tercih ederken, bu araştırmada ise işletmecilerin önemli bir kısmı melez ırk tercih etmişlerdir. Melez ırk tercihi bakımından bu araştırma ile Muş ilinde yapılan araştırma arasında benzerlik bulunmuştur.

Hayvancılığı baba mesleği olarak yapan işletmeciler, ağırlıklı olarak yerli ve melez ırkı yetiştirmektedirler (Çizelge 8). Bu işletmeciler mevcut irkların aksine $\% 67.1$ oranında kültür ırkı tercih etmekte ve \%23.2 oranında ise melez ırkını tercih ettikleri belirlenmiştir. Başka iş olmadığı için hayvancılık yapan işletmecilerin melez ve yerli ırk ağırlıklı yetiştiricilik yapmalarına rağmen irk tercihlerinde kültür ırkının ilk sırayı aldıkları belirlenmiştir.

Muş ilinde Bakır ve Kibar, (2019) tarafından yapılan araştırmada süt sığırcılığı yapan işletmecilerin hayvancılık yapma sebepleri ile tercih ettikleri irk arasında önemli bir ilişki bulunmuştur. Buna göre, hayvancıllı̆̆ı sevdiği, baba mesleği, başka iş olmadığı için yapanlar ile bunların kombinasyonlarından oluşan grupların yüksek oranda kültür ırkını tercih ettikleri ve bu durumun kültür irklarının veriminin yüksek olmasından kaynaklandığı bildirilmektedir. Ayrıca, tüm işletmecilerin kültür ırkları içinde de yüksek oranda Simental ırkı tercih ettiği görülmektedir. Bunun da yetiştiriciler arasındaki iletişimden kaynaklı olduğu düşünülmektedir. Muş ilinde yapılan araştırmada, hayvancılığı baba mesleği olarak yapan işletmecilerin yüksek oranda kültür ırkını tercih etmelerine rağmen, bu araştırmada ise ağırlıklı olarak yerli ve melez irk tercih etmeleri dikkat çekici bulunmuştur.

İşletmecilerin hayvancılığı sürdürme nedenleri arasında, hayvancılığ karlı olduğu için sürdürenlerin kültür ve melez ırkını yetiştirdikleri ve yine ilk sırada kültür ırkını tercih ettikleri ve bunu melez irkın izlediği belirlenmiştir (Çizelge 9). Başka iş olmadığı için hayvancılığı sürdüren işletmecilerin ağırlıklı olarak yerli ve melez irk yetiştirdikleri halde, irk tercihinde ilk sırada kültür irkı ve sonra melez irk tercih ettikleri belirlenmiştir. İşletmecilerin kültür ırkları içinde ilk sırada simental ırkını tercih etmelerinin, bu irkın süt veriminin tatmin edici olması yanında erkeklerinin de besi performansının iyi olmasından kaynaklandığı düşünülmektedir. Muş ilinde Bakır ve Kibar (2019) tarafindan yapılan araştırmada, hayvancılığı sürdürmek isteyen işletmecilerin, ırk tercihi en çok kültür ırkı (\%69.4) ve melezleri (\%27.6) yönünde olurken, kültür ırkları arasında da en fazla Simental irkının (\%76.4) tercih edildiği bildirilmektedir. Edirne ili ve ilçelerindeki işletmelerin süt sığırcılığı yapma nedenlerini \%47.4'ünün geçim sağlamak amacı ile kalanının ise ek gelir sağlamak amacıyla süt sığırcıllğı yaptığı bildirilmektedir (Önal ve Özder, 2008). 
Cizelge 4. İşletmelerin mevcut ırkı ve ırk tercihinin hayvancılık yapılan süreye göre değişimi

Table 4. The change of current breed and breed preference of farms according to the time of making livestock of farmers

\begin{tabular}{|c|c|c|c|c|c|c|c|c|c|c|c|c|c|c|c|}
\hline \multirow{2}{*}{\multicolumn{2}{|c|}{$\begin{array}{l}\text { Hayvancilık } \\
\text { süresi } \\
\text { (the time of } \\
\text { making } \\
\text { livestock) }\end{array}$}} & \multicolumn{5}{|c|}{ Mevcut-(Current breed) } & \multirow[b]{2}{*}{$\begin{array}{c}\text { Topla } \\
\mathrm{m} \\
\text { (Total) }\end{array}$} & \multicolumn{3}{|c|}{ Irk tercihi-(Breed preferrence) } & \multirow[b]{2}{*}{$\begin{array}{c}\text { Topla } \\
\text { m } \\
\text { (Total) }\end{array}$} & \multicolumn{3}{|c|}{$\begin{array}{c}\text { Kültür ırkı tercihi-(Culture breed } \\
\text { preferrence) }\end{array}$} & \multirow[b]{2}{*}{$\begin{array}{c}\text { Topla } \\
\mathrm{m} \\
\text { (Total) }\end{array}$} \\
\hline & & $\begin{array}{c}\text { Yerli } \\
\text { (Domestic) } \\
1\end{array}$ & 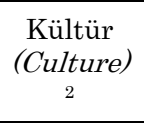 & $\begin{array}{c}\text { Melez } \\
\text { (Crossbreed) } \\
3\end{array}$ & $\begin{array}{l}\text { Yerli+Mele } \\
\mathrm{z}(1+3)\end{array}$ & $\begin{array}{l}\text { Kültür+Mele } \\
\mathrm{z}(2+3)\end{array}$ & & $\begin{array}{c}\text { Yerli } \\
\text { (Domestic } \\
\text { ) }\end{array}$ & $\begin{array}{c}\text { Kültür } \\
\text { (Culture } \\
\text { ) }\end{array}$ & $\begin{array}{c}\text { Melez } \\
\text { (Crossbreed } \\
\text { ) }\end{array}$ & & $\begin{array}{c}\text { Esmer } \\
\left(B . S_{W i S S}\right. \\
)\end{array}$ & $\begin{array}{c}\text { Simental } \\
\text { (Simmental }\end{array}$ & $\begin{array}{l}\text { S. Alaca } \\
\text { (Holstein } \\
\text { ) }\end{array}$ & \\
\hline \multirow{2}{*}{$10>$} & $\begin{array}{l}\text { Ade } \\
\mathrm{t}\end{array}$ & 24 & 11 & 38 & 11 & 6 & 90 & 12 & 56 & 21 & 89 & 11 & 57 & 12 & 80 \\
\hline & $\%$ & 26.7 & 12.2 & 42.2 & 12.2 & 6.7 & 100 & 13.5 & 62.9 & 23.6 & 100 & 13.8 & 71.3 & 15 & 100 \\
\hline \multirow[t]{2}{*}{$11-20$} & $\begin{array}{l}\text { Ade } \\
\mathrm{t}\end{array}$ & 24 & 13 & 38 & 9 & 7 & 91 & 8 & 60 & 22 & 90 & 8 & 59 & 12 & 79 \\
\hline & $\%$ & 26.4 & 14.3 & 41.8 & 9.9 & 7.7 & 100 & 8.9 & 66.7 & 24.4 & 100 & 10.1 & 74.7 & 15.2 & 100 \\
\hline \multirow[t]{2}{*}{$21-30$} & $\begin{array}{l}\text { Ade } \\
\mathrm{t}\end{array}$ & 17 & 7 & 14 & 9 & 1 & 47 & 7 & 29 & 11 & 47 & 5 & 32 & 5 & 42 \\
\hline & $\%$ & 36.2 & 14.9 & 29.8 & 19.1 & 2.1 & 100 & 14.9 & 61.7 & 23.4 & 100 & 11.9 & 76.2 & 11.9 & 100 \\
\hline \multirow{2}{*}{$31<$} & $\begin{array}{l}\text { Ade } \\
\mathrm{t}\end{array}$ & 7 & 1 & 12 & 1 & 1 & 22 & 5 & 13 & 4 & 22 & 5 & 9 & 2 & 16 \\
\hline & $\%$ & 31.8 & 4.5 & 54.5 & 4.5 & 4.5 & 100 & 22.7 & 59.1 & 18.2 & 100 & 31.3 & 56.3 & 12.5 & 100 \\
\hline \multirow{2}{*}{$\begin{array}{l}\text { Topla } \\
\mathrm{m} \\
\text { (Total) }\end{array}$} & $\begin{array}{l}\text { Ade } \\
\mathrm{t}\end{array}$ & 72 & 32 & 102 & 30 & 15 & 250 & 32 & 158 & 58 & 248 & 29 & 157 & 31 & 217 \\
\hline & $\%$ & 28.8 & 12.8 & 40.8 & 12.0 & 6 & 100 & 12.9 & 63.7 & 23.4 & 100 & 13.4 & 72.4 & 14.3 & 100 \\
\hline
\end{tabular}

Çizelge 5. İşletmelerin mevcut ırkı ve ırk tercihinin işletme tipine göre değişimi

Table 5. The change of current breed and breed preference of farms according to the type of farms

\begin{tabular}{|c|c|c|c|c|c|c|c|c|c|c|c|c|c|c|c|}
\hline \multirow{2}{*}{\multicolumn{2}{|c|}{$\begin{array}{l}\text { İsletme tipi } \\
\text { (the type of farms) }\end{array}$}} & \multicolumn{5}{|c|}{ Mevcut-(Current breed) } & \multirow{2}{*}{$\begin{array}{r}\text { Toplam } \\
\text { (Total) }\end{array}$} & \multicolumn{3}{|c|}{ Irk tercihi-Breed preference } & \multirow{2}{*}{$\begin{array}{r}\text { Toplam } \\
\text { (Total) }\end{array}$} & \multicolumn{3}{|c|}{$\begin{array}{c}\text { Kültür ırkı tercihi-(Cultur breed } \\
\text { preferrence) }\end{array}$} & \multirow{2}{*}{$\begin{array}{r}\text { Toplam } \\
\text { (Total) }\end{array}$} \\
\hline & & $\begin{array}{c}\text { Yerli } \\
\text { (Domestic }\end{array}$ & $\begin{array}{l}\text { Kültür } \\
\text { Culture }\end{array}$ & $\begin{array}{c}\text { Melez } \\
\text { (Crossbreed }\end{array}$ & Yerli+Melez & Kültür +Melez & & Yerli & Kültür & Melez & & $\begin{array}{l}\text { Esmer } \\
\left(B S_{\text {WiSS }}\right.\end{array}$ & $\begin{array}{l}\text { Simental } \\
\text { Simmental }\end{array}$ & $\begin{array}{l}\text { S. Alaca } \\
\text { (Holstein }\end{array}$ & \\
\hline \multirow{4}{*}{$\begin{array}{l}\text { Süt } \\
\text { siğırcıllğ } \\
\text { (Dairy } \\
\text { cattle) } \\
\text { Kombine } \\
\text { işletme } \\
\text { (Combine } \\
\text { farm) }\end{array}$} & $\begin{array}{l}\text { Ade } \\
\mathrm{t}\end{array}$ & 52 & 31 & 81 & 24 & 11 & 199 & 25 & 130 & 42 & 197 & 22 & 123 & 31 & 176 \\
\hline & $\%$ & 26.1 & 15.6 & 40.7 & 12.1 & 5.5 & 100 & 12.7 & 66 & 21.3 & 100 & 12.5 & 69.9 & 17.6 & 100 \\
\hline & $\begin{array}{l}\text { Ade } \\
t\end{array}$ & 20 & 1 & 21 & 5 & 4 & 51 & 7 & 28 & 16 & 51 & 7 & 34 & 0 & 41 \\
\hline & $\%$ & 39.2 & 2 & 41.2 & 9.8 & 7.8 & 100 & 13.7 & 54.9 & 31.4 & 100 & 17.1 & 82.9 & 0.0 & 100 \\
\hline \multirow{2}{*}{$\begin{array}{l}\text { Toplam } \\
\text { (Total) }\end{array}$} & $\begin{array}{l}\text { Ade } \\
t\end{array}$ & 72 & 32 & 102 & 29 & 15 & 250 & 32 & 158 & 58 & 248 & 29 & 157 & 31 & 217 \\
\hline & $\%$ & 28.8 & 12.8 & 40.8 & 11.6 & 6 & 100 & 12.9 & 63.7 & 23.4 & 100 & 13.4 & 72.4 & 14.3 & 100 \\
\hline
\end{tabular}


Cizelge 6. İşletmelerin mevcut ırkı ve ırk tercihinin hayvan sayısına göre değişimi

Table 6. The change of current breed and breed preference of farms according to the animal number of farms

\begin{tabular}{|c|c|c|c|c|c|c|c|c|c|c|c|c|c|c|c|}
\hline \multirow{2}{*}{\multicolumn{2}{|c|}{$\begin{array}{l}\text { Hayvan sayısı } \\
\text { (the animal } \\
\text { number })\end{array}$}} & \multicolumn{5}{|c|}{ Mevcut $-($ Current breed $) * *$} & \multirow[b]{2}{*}{$\begin{array}{r}\text { Toplam } \\
\text { (Total) }\end{array}$} & \multicolumn{3}{|c|}{ Irk tercihi-(Breed preferrence)* } & \multirow[b]{2}{*}{$\begin{array}{r}\text { Toplam } \\
\text { (Total) }\end{array}$} & \multicolumn{3}{|c|}{$\begin{array}{l}\text { Kültür ırkı tercihi-(Culture breed } \\
\text { preferrence) }\end{array}$} & \multirow[b]{2}{*}{$\begin{array}{r}\text { Toplam } \\
\text { (Total) }\end{array}$} \\
\hline & & $\begin{array}{c}\text { Yerli } \\
(\text { Domestic) }\end{array}$ & $\begin{array}{l}\text { Kültür } \\
\text { (Culture) }\end{array}$ & $\begin{array}{c}\text { Melez } \\
\text { (Crossbreed) }\end{array}$ & $\begin{array}{l}\text { Yerli+Melez } \\
\quad(1+3)\end{array}$ & $\begin{array}{l}\text { Kültür } \\
+ \text { Melez } \\
(2+3) \\
\end{array}$ & & $\begin{array}{r}\text { Yerli } \\
\text { (Domestic) }\end{array}$ & $\begin{array}{r}\text { Kültür } \\
\text { (Culture) }\end{array}$ & $\begin{array}{r}\text { Melez } \\
\text { (Crossbreed) }\end{array}$ & & $\begin{array}{c}\text { Esmer } \\
\text { (B.Swiss })\end{array}$ & $\begin{array}{c}\text { Simental } \\
\text { (Simmental) }\end{array}$ & $\begin{array}{l}\text { S. Alaca } \\
\text { (Holstein) }\end{array}$ & \\
\hline \multirow{2}{*}{$2>$} & Adet & 28 & 1 & 28 & 3 & 0 & 60 & 12 & 28 & 19 & 59 & 9 & 27 & 11 & 47 \\
\hline & $\%$ & 46.7 & 1.7 & 46.7 & 5 & 0 & 100 & 20.3 & 47.5 & 32.2 & 100 & 19.1 & 57.4 & 23.4 & 100 \\
\hline \multirow{2}{*}{$3-5$} & Adet & 33 & 17 & 49 & 11 & 4 & 114 & 13 & 72 & 28 & 113 & 14 & 74 & 13 & 101 \\
\hline & $\%$ & 28.9 & 14.9 & 43 & 9.6 & 3.5 & 100 & 11.5 & 63.7 & 24.8 & 100 & 13.9 & 73.3 & 12.9 & 100 \\
\hline \multirow{2}{*}{$6-10$} & Adet & 10 & 5 & 16 & 9 & 8 & 48 & 7 & 35 & 6 & 48 & 5 & 35 & 2 & 42 \\
\hline & $\%$ & 20.8 & 10.4 & 33.3 & 18.8 & 16.7 & 100 & 14.6 & 72.9 & 12.5 & 100 & 11.9 & 83.3 & 4.8 & 100 \\
\hline \multirow{2}{*}{$11+$} & Adet & 1 & 9 & 9 & 6 & 3 & 28 & 0 & 23 & 5 & 28 & 1 & 21 & 5 & 27 \\
\hline & $\%$ & 3.6 & 32.1 & 32.1 & 21.4 & 10.7 & 100 & 0 & 82.1 & 17.9 & 100 & 3.7 & 77.8 & 18.5 & 100 \\
\hline \multirow{2}{*}{$\begin{array}{l}\text { Toplam } \\
\text { (Total) }\end{array}$} & Adet & 72 & 32 & 102 & 29 & 15 & 250 & 32 & 158 & 58 & 248 & 29 & 157 & 31 & 217 \\
\hline & $\%$ & 28.8 & 12.8 & 40.8 & 11.6 & 6 & 100 & 12.9 & 63.7 & 23.4 & 100 & 13.4 & 72.4 & 14.3 & 100 \\
\hline
\end{tabular}

$* * \mathrm{p}<0.01$

Çizelge 7. İşletmelerin ırk tercihinin mevcut ırka göre değişimi

Table 7. The change of current breed and breed preference of farms according to the current breed of farms

\begin{tabular}{|c|c|c|c|c|c|c|c|c|c|}
\hline \multirow{2}{*}{ Mevcut-(Current breed) } & & \multicolumn{3}{|c|}{ 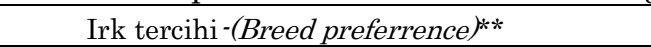 } & \multirow[b]{2}{*}{$\begin{array}{r}\text { Toplam } \\
\text { (Total) }\end{array}$} & \multicolumn{3}{|c|}{ Kültür ırkı tercihi-(Cultur breed preferrence) } & \multirow[b]{2}{*}{$\begin{array}{r}\text { Toplam } \\
\text { (Total) }\end{array}$} \\
\hline & & $\begin{array}{r}\text { Yerli } \\
\text { (Domestic) }\end{array}$ & $\begin{array}{r}\text { Kültür } \\
\text { (Culture) } \\
\end{array}$ & $\begin{array}{r}\text { Melez } \\
\text { (Crossbreed) }\end{array}$ & & $\begin{array}{c}\text { Esmer } \\
\text { (B.SWiSS }) \\
\end{array}$ & $\begin{array}{c}\text { Simental } \\
\text { (Simmental) }\end{array}$ & $\begin{array}{l}\text { S. Alaca } \\
\text { (Holstein) }\end{array}$ & \\
\hline \multirow{2}{*}{ Yerli (Domestic) } & Adet & 31 & 21 & 19 & 71 & 7 & 32 & 5 & 44 \\
\hline & $\%$ & 43.7 & 29.6 & 26.8 & 100.0 & 15.9 & 72.7 & 11.4 & 100.0 \\
\hline \multirow{2}{*}{ Kültür (Culture) } & Adet & 0 & 31 & 1 & 32 & 2 & 25 & 5 & 32 \\
\hline & $\%$ & 0.0 & 96.9 & 3.1 & 100.0 & 6.3 & 78.1 & 15.6 & 100.0 \\
\hline \multirow{2}{*}{ Melez (Crossbreed) } & Adet & 1 & 74 & 26 & 101 & 16 & 65 & 16 & 97 \\
\hline & $\%$ & 1.0 & 73.3 & 25.7 & 100.0 & 16.5 & 67.0 & 16.5 & 100.0 \\
\hline \multirow{2}{*}{$\begin{array}{l}\text { Yerli+Melez } \\
\text { (Domestic }+ \text { Crossbreed) }\end{array}$} & Adet & 0 & 18 & 11 & 29 & 4 & 20 & 5 & 29 \\
\hline & $\%$ & 0.0 & 62.1 & 37.9 & 100.0 & 13.8 & 68.9 & 17.3 & 100.0 \\
\hline \multirow{2}{*}{$\begin{array}{l}\text { Kültür +Melez } \\
\text { (Culture+Crossbreed) }\end{array}$} & Adet & 0 & 14 & 1 & 15 & 0 & 15 & 0 & 15 \\
\hline & $\%$ & 0.0 & 93.3 & 6.7 & 100.0 & 0.0 & 100.0 & 0.0 & 100.0 \\
\hline \multirow{2}{*}{ Toplam (Total) } & Adet & 32 & 158 & 58 & 248 & 29 & 157 & 31 & 217 \\
\hline & $\%$ & 12.9 & 63.7 & 23.4 & 100.0 & 13.4 & 72.4 & 14.3 & 100.0 \\
\hline
\end{tabular}


Çizelge 8. İşletmelerin mevcut ırkı ve ırk tercihinin hayvancılık yapma nedenine göre değişimi

Table 8. The change of current breed and breed preference of farms according to the reason of making livestock of farms

\begin{tabular}{|c|c|c|c|c|c|c|c|c|c|c|c|c|c|c|c|}
\hline \multirow{2}{*}{\multicolumn{2}{|c|}{$\begin{array}{l}\text { Hayvancilık yapma } \\
\text { nedeni (the reason } \\
\text { of making } \\
\text { livestock) }\end{array}$}} & \multicolumn{5}{|c|}{ Mevcut-(Current breed) } & \multirow[b]{2}{*}{$\begin{array}{r}\text { Toplam } \\
\text { (Total) }\end{array}$} & \multicolumn{3}{|c|}{ Irk tercihi-(Breed preferrence) } & \multirow[b]{2}{*}{$\begin{array}{l}\text { Toplam } \\
\text { (Total) }\end{array}$} & \multicolumn{3}{|c|}{$\begin{array}{c}\text { Kültür ırkı tercihi-(Cultur breed } \\
\text { preferrence) }\end{array}$} & \multirow[b]{2}{*}{$\begin{array}{l}\text { Toplam } \\
\text { (Total) }\end{array}$} \\
\hline & & $\begin{array}{c}\text { Yerli } \\
(\text { Domestic })^{1}\end{array}$ & $\begin{array}{c}\text { Kültür } \\
\text { (Culture) }\end{array}$ & $\begin{array}{c}\text { Melez } \\
\text { (Crossbreed })^{\beta}\end{array}$ & $\begin{array}{c}\text { Yerli+Melez } \\
(1+3)\end{array}$ & $\begin{array}{c}\text { Kültür } \\
+ \text { Melez }(2+3) \\
\end{array}$ & & $\begin{array}{c}\text { Yerli } \\
\text { (Domestic) }\end{array}$ & $\begin{array}{c}\text { Kültür } \\
\text { (Culture) }\end{array}$ & $\begin{array}{c}\text { Melez } \\
\text { (Crossbreed) }\end{array}$ & & $\begin{array}{c}\text { Esmer } \\
\text { (B.SWisS })\end{array}$ & $\begin{array}{c}\text { Simental } \\
\text { (Simmental) }\end{array}$ & $\begin{array}{l}\text { S. Alaca } \\
\text { (Holstein) }\end{array}$ & \\
\hline \multirow{2}{*}{$\begin{array}{l}\text { Baba } \\
\text { mesleği } \\
\text { (Father's } \\
\text { profession) }\end{array}$} & Adet & 23 & 8 & 36 & 12 & 5 & 84 & 8 & 55 & 19 & 82 & 8 & 56 & 9 & 73 \\
\hline & $\%$ & 27.4 & 9.5 & 42.9 & 14.3 & 6 & 100 & 9.8 & 67.1 & 23.2 & 100 & 11 & 76.7 & 12.3 & 100 \\
\hline \multirow{2}{*}{$\begin{array}{l}\text { Sevdiği için } \\
\text { (Likes } \\
\text { livestock) }\end{array}$} & Adet & 8 & 10 & 17 & 7 & 2 & 44 & 3 & 28 & 13 & 44 & 7 & 27 & 6 & 40 \\
\hline & $\%$ & 18.2 & 22.7 & 38.6 & 15.9 & 4.5 & 100 & 6.8 & 63.6 & 29.5 & 100 & 17.5 & 67.5 & 15 & 100 \\
\hline \multirow{2}{*}{$\begin{array}{l}\text { Başka iş yok } \\
\text { (No more } \\
\text { jobs) }\end{array}$} & Adet & 41 & 14 & 49 & 10 & 8 & 122 & 21 & 75 & 26 & 122 & 14 & 74 & 16 & 104 \\
\hline & $\%$ & 33.6 & 11.5 & 40.2 & 8.2 & 6.6 & 100 & 17.2 & 61.5 & 21.3 & 100 & 13.5 & 71.2 & 15.4 & 100 \\
\hline \multirow{2}{*}{$\begin{array}{l}\text { Toplam } \\
\text { (Total) }\end{array}$} & Adet & 72 & 32 & 102 & 29 & 15 & 250 & 32 & 158 & 58 & 248 & 29 & 157 & 31 & 217 \\
\hline & $\%$ & 28.8 & 12.8 & 40.8 & 11.6 & 6 & 100 & 12.9 & 63.7 & 23.4 & 100 & 13.4 & 72.4 & 14.3 & 100 \\
\hline
\end{tabular}

Çizelge 9. İşletmelerin mevcut ırkı ve ırk tercihinin hayvancılı̆̆ı sürdürme nedenine göre değişimi

Table 9. The change of current breed and breed preference of farms according to the reason of maintaining livestock of farmers

\begin{tabular}{|c|c|c|c|c|c|c|c|c|c|c|c|c|c|c|c|}
\hline \multirow{2}{*}{\multicolumn{2}{|c|}{$\begin{array}{l}\text { Hayvancilığı } \\
\text { sürdürme nedeni (the } \\
\text { reason of maintaining } \\
\text { livestock) }\end{array}$}} & \multicolumn{5}{|c|}{ Mevcut-(Current breed) } & \multirow[b]{2}{*}{$\begin{array}{c}\text { Toplam } \\
\text { (Total) }\end{array}$} & \multicolumn{3}{|c|}{ Irk tercihi-(Breed preference) } & \multirow[b]{2}{*}{$\begin{array}{c}\text { Toplam } \\
\text { (Total) }\end{array}$} & \multicolumn{3}{|c|}{$\begin{array}{c}\text { Kültür ırkı tercihi } \\
\text { (Cultur breed preferrence) }\end{array}$} & \multirow[b]{2}{*}{$\begin{array}{r}\text { Toplam } \\
\text { (Total) }\end{array}$} \\
\hline & & $\begin{array}{c}\text { Yerli } \\
\text { (Domestic } \\
\wedge\end{array}$ & $\begin{array}{l}\text { Kültür } \\
\text { (Culture } \\
\qquad \\
\end{array}$ & $\begin{array}{c}\text { Melez } \\
\text { (Crossbreed) }\end{array}$ & $\begin{array}{l}\text { Yerli+Mele } \\
\mathrm{z}(1+3)\end{array}$ & $\begin{array}{l}\text { Kültür+Mel } \\
\text { ez }(2+3)\end{array}$ & & $\begin{array}{c}\text { Yerli } \\
\text { (Domestic } \\
\text { ) }\end{array}$ & $\begin{array}{c}\text { Kültür } \\
\text { (Culture } \\
\text { ) }\end{array}$ & $\begin{array}{c}\text { Melez } \\
\text { (Crossbreed) }\end{array}$ & & $\begin{array}{c}\text { Esmer } \\
\left(B . S_{\text {wiSS }}\right. \\
)\end{array}$ & $\begin{array}{c}\text { Simental } \\
\text { (Simmental) }\end{array}$ & $\begin{array}{l}\text { S. Alaca } \\
\text { (Holstein } \\
\text { ) }\end{array}$ & \\
\hline \multirow{2}{*}{$\begin{array}{l}\text { Karl } \\
\text { (Profitability) }\end{array}$} & $\begin{array}{l}\text { Ade } \\
\mathrm{t}\end{array}$ & 1 & 7 & 8 & 2 & 4 & 22 & 0 & 17 & 5 & 22 & 3 & 16 & 2 & 21 \\
\hline & $\%$ & 4.5 & 31.8 & 36.4 & 9.1 & 18.2 & 100 & 0 & 77.3 & 22.7 & 100 & 14.3 & 76.2 & 9.5 & 100 \\
\hline \multirow{2}{*}{$\begin{array}{l}\text { Bana yetiyor } \\
\text { (Sufficient for } \\
\text { me) }\end{array}$} & $\begin{array}{l}\text { Ade } \\
t\end{array}$ & 17 & 8 & 17 & 7 & 3 & 52 & 5 & 31 & 16 & 52 & 7 & 28 & 9 & 44 \\
\hline & $\%$ & 32.7 & 15.4 & 32.7 & 13.4 & 5.8 & 100 & 9.6 & 59.6 & 30.8 & 100 & 15.9 & 63.6 & 20.5 & 100 \\
\hline \multirow{2}{*}{$\begin{array}{l}\text { Başka işi yok } \\
\text { (No more jobs) }\end{array}$} & $\begin{array}{l}\text { Ade } \\
\mathrm{t}\end{array}$ & 35 & 11 & 43 & 12 & 5 & 106 & 18 & 64 & 23 & 105 & 12 & 65 & 12 & 89 \\
\hline & $\%$ & 33.0 & 10.4 & 40.6 & 11.3 & 4.7 & 100 & 17.1 & 61 & 21.9 & 100 & 13.5 & 73.0 & 13.5 & 100 \\
\hline \multirow{2}{*}{$\begin{array}{l}\text { Hayvancılığı } \\
\text { seviyor } \\
\text { (Likes livestock) }\end{array}$} & $\begin{array}{l}\text { Ade } \\
\mathrm{t}\end{array}$ & 5 & 2 & 11 & 2 & 0 & 20 & 2 & 10 & 7 & 19 & 5 & 11 & 2 & 18 \\
\hline & $\%$ & 25 & 10 & 55 & 10 & 0 & 100 & 10.5 & 52.6 & 36.8 & 100 & 27.8 & 61.1 & 11.1 & 100 \\
\hline \multirow{2}{*}{ Toplam (Total) } & $\begin{array}{l}\text { Ade } \\
t\end{array}$ & 58 & 28 & 79 & 23 & 12 & 200 & 25 & 122 & 51 & 198 & 27 & 120 & 25 & 172 \\
\hline & $\%$ & 29 & 14 & 39.5 & 11.5 & 6 & 100 & 12.6 & 61.6 & 25.8 & 100 & 15.7 & 69.8 & 14.5 & 100 \\
\hline
\end{tabular}


$\mathrm{Bu}$ araştırmada bulunan sonuç ile Bakır ve Kibar (2019) tarafindan bildirilen araştırma sonucu arasında önemli benzerlik bulunmuştur.

\section{SONUÇ ve ÖNERILER}

İşletmeler yerli ve melez ağırlıklı ırklarla yetiştircilik yaparken, ırk tercihinde ise ağırlıklı olarak (\%63.7) kültür ırkını tercih etmişlerdir. Kültür ırkı içinde ise en fazla Simental rrkı tercih edilirken, bunu Siyah Alaca ve Esmer ırkları izlemiştir. İşletmelerde rrk tercihine işletmecilerin eğitim durumu, yaşı, hayvancılık yaptığı süre, hayvancılık yapma ve sürdürme nedenleri ile işletmelerin tipi, mevcut hayvan varlığı ve ırkı etkili olmuştur. Yerli ırkı tercih eden işletmecilerin genelde yaşlı, okuryazar olmayan ve/veya ilkokul eğitimine sahip oldukları; hayvancılığı ev ihtiyaçlarını karşılamak ya da ev ekonomisine katkıda bulunmak amacıyla yaptıkları belirlenmiştir. Ayrıca, yörede mera alanlarının yetersiz olması ve yem bitkisi ekiminin yetersiz olması, kaba yem kaynaklarının kıt olması ve kesif yemin pahalı olması nedeni ile yerli irk tercih ettikleri anlaşılmıştır. Kültür melezini tercih eden yetiştiricilerin işletme şartlarının nispeten yeterli olduğu ve işletmecilerin yetiştiricilik bilgi ve tecrübelerinin genel itibariyle iyi olduğu belirlenmiştir. Ayrıca, işletmeciler melez ırkları yetersiz çevre şartlarına kültür ırklarından daha dayanıklı olduğu ve et-süt verimlerinin de yerli rrklardan daha iyi olduğu için tercih ettikleri belirlenmiştir. Kültür ırkını tercih eden işletmecilerin genç ve orta yaşlı, orta ve üzeri eğitime sahip oldukları; işletmelerin ise süt sığırcılığg için alt yapı ve bakım besleme imkânlarının daha elverişli olduğu görülmüştür. Ayrıca, bu işletmelerin tamamen ticari amaçlı olarak sığırcılık yaptıkları ve gelir kaynaklarının büyük bir bölümünü süt sığırcılığından karşıladıkları için yüksek verimli kültür ırklarıyla sığgrıcılık yaptıkları belirlenmiştir. Sonuç olarak, işletmelerin fiziki şartlarının iyileşmesi, bakım ve besleme ile yetiştiricilerin bilgi ve tecrübelerinin artması yanında elde edilen gelirin artması ile işletmelerin $\mathrm{rk}$ tercihlerinde değişme olacağ 1 kanaatine varılmıştır.

\section{Çıkar Çatışması Beyanı}

Makale yazarları aralarında herhangi bir çıkar çatışması olmadığını beyan ederler.

\section{Araştırmacıların Katkı Oranı Beyan Özeti}

İkinci yazar, anket çalışmasını ve veri girişini yapmıştır. Makalenin istatistik analizleri, bulgular ve tartışması gibi diğer işleri sorumlu yazar tarafından yapılmıştır.

\section{KAYNAKLAR}

Arıkan R 2000. Araştırma Teknikleri ve Rapor Yazma. Gazi Kitapevi, 312s., Ankara

Bakan Ö, Aydın R 2016. Ağrı İli Süt Sığırcılığı İşletmelerinin Sosyo-Ekonomik Özellikleri. Journal of theFaculty of Agriculture 47(2):113-122.

Bakır G 2002a. Van İlindeki Özel Süt Sığırcılığı İşletmelerinde Tercih Edilen Kültür Irkları. YYÜ Tarım Bilimleri Dergisi 12(2): 11-20.

Bakır G 2002b.Van İlindeki Özel Süt Sığırcılığg İşletmelerinin Yapısal Durumu. YYÜ Tarım Bilimleri Dergisi 12(2): 1-10.

Bakır, G., Kibar M 2019. Muş İlinde Süt Sığırcılığı İşletmelerinde Irk Tercihi ve Etkileyen Faktörler. Mediterrian Agricultural Sciences 32(2): 257-262

Cochran WG 1977. Sampling Techniques (3rd Edition). John Wiley\&Sons. New York. https://www. academia.edu/29684662/ Cochran 1977_Sampling_ Techniques Third_Edition. pdf. (Erişim: 14.01.2019).

Daş A, İnci H, Karakaya E, Şengül AY 2014. Bingöl İli Damızlık Sığır Yetiştiricileri Birliğine Bağlı Sığırcılık İşletmelerinin Mevcut Durumu. Türk Tarım ve Doğa Bilimleri Dergisi 1(3): 421-429.

Düzgüneş O, Kesici T, Gürbüz F 1983. İstatistik Metodları I. A.Ü. Ziraat Fak. Yay. No:229.

Güler O, Aydın R, Yanar M, Diler A, Koçyiğit R, Avcı M 2016. Erzurum ili Hınıs İlçesi Sığırcılık İsletmelerinin Sosyo-Ekonomik Yapısı. Alınteri Zirai Bilimler Dergisi 30(1): 27-37.

Han Y, Bakır G 2009. Özel Besi Siğırcılığ İşletmelerinde Irk Tercihleri ve Besi Uygulamaları. Atatürk Üniv. Ziraat Fak. Dergisi 40(2): 35-41.

Ildız F 1999. Tokat İli Merkez İlçesinde İthal Sığır Yetiştiren Tarım İşletmelerinin Yapısı. Ankara Üniv. Fen Bil. Ens. Zootekni Anabilim Dalı, Yüksek Lisans Tezi, 77s.

Kaygisız A, Tümer R, Orhan H, Vanlı Y 2008. Kahramanmaraş Bölgesi Süt Siğırcılık İşletmelerinin Yapısal Özellikleri: 1. Yetiştirme Uygulamaları. Süleyman Demirel Üniv. Ziraat Fakültesi Dergisi 3(2): 23-31.

Koçyiğit R, Yanar M, Diler A, Güler O, Aydın R 2017. Erzurum ili Narman İlçesindeki Siğırcılık İşletmelerinde Uygulanan Sağım Yönetimi Üzerine Bir Araştırma. Alınteri J. Agricultural Sciences 32(2): 45-54.

Köseman A, Şeker İ 2016. Malatya İlinde Sığırcılık İşletmelerinin Mevcut Durumu: I. Yapısal özellikler. Fırat Üniv. Sağlık Bilimleri Dergisi 30(1): 5-12.

Önal AR, Özder M 2008. Edirne İli Damızlık Sığır Yetiştiricileri Birliğine Üye İşletmelerin Yapısal Özellikleri. Tekirdağ Ziraat Fakültesi Dergisi, 5 (2): 197-203.

Öztürk NN 2009. Mardin İlindeki Süt Sı̆̆ırcılığı İşletmelerinin Yapısal Özellikleri. SÜ Fen 
Bilimleri Enstitüsü, Zootekni Anabilim Dall, Yüksek Lisans Tezi, 65s.

Özyürek S, Koçyiğit R, Tüzemen N 2014. Erzincan İlinde Süt Sığırcılığ Yapan İşletmelerin Yapısal Özellikleri: Çayırlı İlçesi Örneği. Tekirdağ Ziraat Fakültesi Dergisi 11(3): 19-26.

Savaş S, Yenice G 2016. Rize İlinde Yapılan Süt Sığırcılığının Mevcut Durumunun Araştırılması. Atatürk Üniv. Veteriner Bilimleri Derg 11(1): 7483.

Sümbüloğlu K, Sümbüloğlu V 2007. Biyoistatistik. Hatipoğlu Yayınları, Ankara.

Şeker İ, Tasalı H, Güler H 2012. Muş İlinde Sığır Yetiştiriciliği Yapılan İşletmelerin Yapısal Özellikleri. FÜ Sağlık Bilimleri Veteriner Dergisi 26(1): 9-16.

Tugay A, Bakır G 2006. Giresun Yöresindeki Özel Süt Sığırcılığ 1 İşletmelerinin Irk Tercihleri ve Barınakların Yapısal Durumu. Atatürk Üniv. Ziraat Fakültesi Dergisi 37(1): 39-47.

Tugay A, Bakır G 2008. Giresun Yöresindeki
Sığırcılık İşletmelerinde Kullanılan Yem Çeşitleri ve Hayvan Besleme Alışkanlıkları. Atatürk Üniv., Ziraat Fakültesi Dergisi 39(2): 231-239.

Tugay A, Bakır G 2009. Giresun yöresindeki Süt Sığırcılığı İşletmelerinin Yapısal Özellikleri. Atatürk Üniv. Ziraat Fakültesi Derg 40(1): 37-47.

Ünalan A, Serbester U, Çınar M, Ceyhan A, Akyol E, Şekeroğlu A, Erdem T, Yılmaz S 2013. Niğde İli Süt Sığırcılığı İşletmelerinin Mevcut Durumu, Başlıca Sorunları ve Çözüm Önerileri. Türk Tarım- Gida Bilim ve Teknoloji Dergisi 1(2): 67-72.

Yamane T 2006. Temel Örnekleme Yöntemleri. (Çeviri: Esin A, Bakır MA, Aydın C, Güzbüzsel E.) Literatür Yayınları: 53, İstanbul, 411.

Yılmaz İ, Dağıstan E, Koç B, Özel R 2003. Hatay İlinde Projeli ve Projesiz Süt Siğırcılığı Yapan İşletmelerin Süt Sığırcılığı Üretim Faaliyetlerinin ve Faktör Verimliliklerinin Analizi. Mediterranean Agricultural Sciences 16(2): 169178. 